\title{
A Study of High School Students' English Learning Enjoyment (ELE) in China
}

\author{
Yibo Zhi ${ }^{1}$ \& Honggang Liu ${ }^{2}$ \\ ${ }^{1}$ Shenyang No.120 High School, Shenyang City, China \\ ${ }^{2}$ Northeast Normal University, Changchun City, China \\ liuhg213@nenu.edu.cn
}

\begin{abstract}
ARTICLE HISTORY
Received : 2021-07-11

Revised : 2021-10-23

Accepted : 2021-10-25
\end{abstract}

\section{KEYWORDS}

English Learning Enjoyment (ELE)

ELE-Teacher

ELE-Private

ELE-Atmosphere

High school students in China

General levels

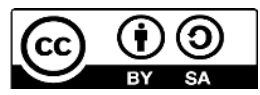

\begin{abstract}
English Learning Enjoyment (ELE) potentially sustains students' motivation of English learning, especially under China's fresh context where National English Curriculum Standards for Senior High Schools issued in 2017 has directed teachers to cultivate students' core competencies of English as a subject. Its theoretical framework was established by Dewaele and MacIntyre (2014) on Foreign Language Enjoyment (FLE) and then subcategorized by Li Chengchen et al. (2018) into ELE-Private, ELE-Teacher, and ELE-Atmosphere. The three dimensions have thus made it possible for the following quantitative research, where an enormous space remains on senior high school students in China, despite exhaustive studies beforehand with either overseas background or distinctive educational contexts. This quantitative study will concentrate on the general levels of ELE, both overall and for each dimension. Thus with Li Chengchen et al.'s (2018) ELE Scale came the investigations of 351 senior high school students of all grades with diverse academic levels, whose data were analyzed through SPSS in terms of general levels (both mean values and standard differentiations). The results have looked at an intermediate and converging level of Overall ELE with a more prominent level of ELE-Teacher than ELE-Private and ELE-Atmosphere. Inspired by the results comes a disclosure of students' positivity in English learning under the guise of their inclination to teachers' efforts instead of automatic drive or constructive environment for authentic language development. Thus an integrated approach is recommended by dint of an elaborate picture of ELE-Private and ELE-Atmosphere to reclaim the lost authentic "self" of senior high school students.
\end{abstract}

\section{Introduction}

Conspicuous disparities between individuals in English learning, from an overlook of complete stages of language acquisition for Chinese English learners, are primarily ascribed to their adaptability to senior high school English study, emotionally or academically. The junction of learners' transformation to the intermediate language level features its more critical requirement of vocabulary storage and its greater complexity in deciphering English texts in reading comprehension tasks. In this case, it has necessitated learners' diverse language competencies as stipulated in the National English Curriculum Standards issued in 2017. Yet stark contrasts have been underlying its guidelines and the student's actual performance, derived from the cumbersome contents to be completed within restrained course schedules and the stratified students' academic levels in senior high schools. The former indicate overdue coverage of indicates knowledge. In contrast, the latter signifies students' discrepancies in their language competencies, be it a failure of English education in their compulsory education period or their burnout of potentials at the present stage. More crucially, however, the latter factor has disclosed various groups of students differentiated not only in the language itself but affectively by dint of their English Learning Enjoyment (ELE), the pivot of this study.

Coined terms from both psychology and Second Language Acquisition (SLA), ELE has constituted one source of students' motivation towards their language proficiencies, frequently embodied in the newly-issued Curriculum Standards, which shall serve as a pillar to guide students throughout their three-year unswerving efforts in language learning. 
For ELE, prototypically a positive emotion, raw speculation can be drawn that an enjoyable atmosphere through appropriate classroom management and a teacher's apposite affections will enable students to experience what other positive emotions in FL or L2 learning shall render, namely to raise the learners' consciousness of language input and perceptions of linguistic forms, and boost their use of multiple problem-solving strategies, thus leading to the enlargement of the learners' language knowledge base (Piechurska-Kuciel, 2017; Boudreau \& Dewaele, 2018; Jin \& Zhang, 2018). It is also conducive to attenuating the effect of negative emotions resulting from language learning difficulties, increasing resilience from setbacks, and forging social bonds in the classroom through active peer-and-teacher relationships generated in their decision-making processes (Dewaele \& Alfawzan, 2018; Jin \& Zhang, 2018).

That said, such positivity has been differentiated from senior high students' status quo on account of the verbatim extrapolation of the term. "Enjoyment," in such conception, has been more interpreted as a parameter that shall determine English learners' (or senior high school students, in this context) resolution of further study than a positive emotion per se. The imperative breaches of conventional perception, in not only the transformed identity of "enjoyment" but also its intuitive hypotheses of an all-rounded positive outlook, have made it a necessity to move off from the stereotype and genuinely probe into the general levels on the three dimensions of ELE, i.e., ELE-Private, ELE-Teacher, \& ELE-Atmosphere based on Li Chengchen et al.'s (2018) study. This will compensate for the significant deficiencies in recent domestic research on ELE or related niches where unity hasn't been reached regarding their interpretation of students' English learning from an emotional perspective. It will also see its previous fuzzy nature segmented based on the three dimensions, thus specifically researching students' emotional status from the interior with proper and scientific parameters.

To this end, a purely quantitative study will be applied in such inception of a more profound exploration of English Learning Emotions for senior high school students in China, where questionnaires based on a comparatively large sample shall refine this study's results in their general levels, as indicated by mean value (M) and normal differentiation (SD). The targeted analysis will be made available to evade double-prone conclusions between positivity and negativity instead of getting down to its development to a specific extent. Hence a balance will be potentially reached utilizing possible adjustments to the favored dimensions to develop a real incentive for their English learning.
Therefore, the current study will be conducted in ways to reveal Chinese senior high school students:

1) General levels of ELE-Private;

2) General levels of ELE-Teacher;

3) General levels of ELE-Atmosphere.

In terms of its format, with ELE detailed by definition and in its related studies, the paper will simulate $\mathrm{Li}$ Chengchen et al.'s (2018) process by dint of an introduction to the current study's research framework and methodology, eventually coming to results and discussions by dimension, as well as its implication to optimize emotional momentum of this learning population.

\section{Literature Review}

\subsection{Definitions of Foreign Language Enjoyment}

The Rooted in positive emotions and epitomizing their traits of positivity in prior correlational studies with Foreign Language Classroom Anxiety (FLCA), Foreign Language Enjoyment (FLE, or English Learning Enjoyment for this study, ELE) has emerged as a burgeoning term somehow with scanty persuasive definitions.

There have been pioneering qualitative studies with learning enjoyment serving as one parameter for probing correlations with another. Still, it was not until the foreign language enjoyment scales developed by Dewaele and MacIntyre (2014). Their large-scale surveys witnessed their focus on anxiety and enjoyment that eventually shed light on its parameters for the subsequent quantitative studies.

The current definitions for learning enjoyment, if combined with the context of this study, will trace down on Csikszentmihalyi (1997, 2004, 2008), who contends that enjoyment, as a critical component of flow experiences, is the emotion that is felt when one not only meets their needs but also surpasses them to accomplish something in their English studies, and will take on unexpected or surprising intellectual focus, heightened attention, and optimal challenge with its occurrence in simple conducts in a language class. By dint of Csikszentmihalyi's concept of the learning experience of flow comes Dewaele and MacIntyre (2018), who has generalized that enjoyment is "indicative of a state in which psychological needs are being met," and in a combination of the primary emotion "joy" by most emotion theorists, "a key part of the family of emotions that surround the core emotion of joy which will be reflected with challenges of certain degrees." 
Definitions from other perspectives cover Pekrun, Elliot, and Maier (2009). They stipulate that in the field of SLA, enjoyment has been examined as a trait-like emotional experience and a state reaction to learning tasks attributed to the perceived control of language learning activities and of the language being learned, with their dichotomy of trait emotion and state emotion and the distinguishing features between dispositional enjoyment and momentary enjoyment which conceptualize a chronic and a specific response respectively. Besides, Piniel and Albert (2018) have referred to delight in their literature review on the control-value theory of achievement emotions by Pekrun, Frenzel, Goetz, and Perry (2007) as "a positive activating and activity-focused emotion with relaxation as its deactivating counterpart" (Pekrun et al., 2007), which, subsumed into positive activating emotions, have been unveiled with its positive relation to students' academic achievement.

Noteworthy is that learning enjoyment has demonstrated its coexistence with principles in other realms such as psychology and ethics. Nevertheless, despite its interdisciplinary nature, its scope of the definition has paled when confronted with its correlational studies with its counterpart of FLA, where ELE was derived after a ponderous number of studies on negative emotions, thus vindicating its necessity for further study of its essence especially in the Chinese context of English learning in high school which shall demonstrate its practical value for researching at an effective level. Quantified measurement for students' emotional degree at unprecedented levels, on the other hand, shall facilitate targeted judgment of their authentic emotional drives and serve as hardened proofs supplemented by qualitative data. Therefore, for this study, Dewaele and MacIntyre's (2018) definition will be implemented through de-structuralizing its theoretical framework into three dimensions, namely ELE-Private, ELE-Teacher, and ELE-Atmosphere if to reinterpret them for the current study, due to its consistency, as defined, with this study's probe into senior high school students' psychological preparation for English learning at whatever their circumstances.

\subsection{Studies on English Language Enjoyment}

Using the majority of studies on ELE, instead of their sole focus on learning enjoyment, have been found to serve as representative parameters for research on positive emotions to measure its influences on the subjects, or referential parameters for correlative studies with its counterpart of anxiety to serve as one of their variables. On the other hand, qualitative studies have been taking their more dominant roles than their quantitative counterparts. The probe into learners or teachers through recording their response to activities in such empirical research, with the contents coded by the preconditions of researchers. Piniel \& Albert (2018) has conducted qualitative research that indicates that the two emotions most frequently experienced by English majors in writing practices are partially related to enjoyment, and it varies not only according to the skill involved but also depending on the context of language use (in class or outside class). Gregersen et al. (2014) has made a heralding study on emotional intelligence of a learner and the other a pre-service teacher, whose analysis shows the interactions of four branches of emotional intelligence with three activities on positive psychology: savoring, three good things, and learned optimism, which has arrived at conclusions of higher attainability of the subjects' possible selves in their reaction to positive psychology interventions, strategic arrangement of activities to encourage participants to reflect on grateful events for savory and learning optimism, and proper awareness of their emotions to facilitate their thinking and comprehend in emotions of both their own and those around them.

The qualitative approach to ELE has not been confined to positive emotions (or psychology) themselves. Carried out by Pavelescu \& Petrić (2018), four case studies of adolescent EFL learners on love and enjoyment in their sociocultural context of Romania had summarized their results as love being the driving force in the learning process compared with enjoyment, creating effective coping mechanisms when there was a lack of enjoyment in specific classroom situations and motivating learners to invest more significant effort into language learning in and out of the classroom. Similar case studies have also been conducted by Oxford \& Cuellar (2014) on the psychology of five Mexican university students learning Chinese in Mexico or China with a narrative approach that led to the conclusion of language learning functioning as a significant journey in self-discovery, rich in positive emotions tied to experiences of engagement, relationship, meaning, and accomplishment.

In contrast to the qualitative approach, researchers are invariably lavish for the quantitative approach due to its persuasiveness and directness in result demonstration guaranteed by properly-designed questionnaires and targeted data analysis. De Smet et al. (2018) has conducted research on probing into the mechanism of the target language in foreign language classes in terms of classroom enjoyment in CLIL and non-CLIL, collecting data from 896 pupils in French-speaking Belgium. Its results indicate that English learners report significantly more enjoyment than Dutch learners. While primary school pupils report stronger emotions, the effects of CLIL and English are much more significant at the secondary level. Dewaele et al. (2017) have probed into the connection between FLE and 
FLCA within a range of internal learner variables and teacher/classroom-specific variables in a particular specific educational context. With FLCA thus seeming less related to teacher and teacher practices than FLE from the results of 189 participants, the research's pedagogical implication lies in teachers' effort to boost FLE rather than worry too much about students' FLCA. Dewaele \& Dewaele (2017) have looked into the dynamic interaction in foreign language classroom anxiety and enjoyment, utilizing a pseudo-longitudinal investigation among pupils between 12 and 18 years old to discover the evolution of both positive and negative emotions of the same 189 foreign language pupils in the former study, its results with little variation in FLCA and a slight increase in FLE when aligned with growing age groups. It also suggests the dynamic nature of the fluctuation of emotions.

Occasioned by common stereotypical perception on language learners' motivation, the hypothesized dichotomy between FLE and FLCA once belonged to a source of significant debate but has somehow been proved a slight overlap between double elements by Dewaele and MacIntyre (2014). In their study of anxiety and enjoyment as the "two faces of Janus," they conducted a classroom-based investigation and analyses based on Likert scale rating of 21 items as well as one of FLCA on eight items extracted from the FLCAS (Horwitz, Horwitz \& Cope, 1986) have come out that levels of FLE were significantly higher than those of FLCA. FLE and FLCA were linked to several such independent variables as participants' perception of their relative level of proficiency within the FL classroom, the number of languages known, education level, number of FLs understudy, age group, and general level of the FL. Alongside with inherent factors of gender and cultural background, participants' views on episodes of enjoyment in the FL class have revealed the importance of teachers' professional and emotional skills and of a supportive peer group and the moment for their consciousness of accomplishment, which will be further justified in the current study. The breached hypothesized dichotomy has disclosed the non-alternate nature between enjoyment and anxiety and made it feasible for quantitative measures to separate research on enjoyment from anxiety with the facilitative construct on both research targets, as there will be zero necessity for a connection built between low level of enjoyment and high level of anxiety, and vice versa.

The combination of the two approaches has also come to a scientifically-conducted study delineated by the dominant subject of FLE v.s. FLCA in the form of interviews, recording, and other non-statistic means of research so that the data-based results will prove its universality. Specifically speaking, an idiodynamic approach to the research enjoyment and anxiety in second language communication by Boudreau et al. (2018) has applied the conglomerated methods where the participants have rated their per-second fluctuations in each emotion while watching a video recording of their tasks after being recruited to finish oral tasks in their second language, and were interviewed about their attributions for fluctuations in their ratings. The dynamic relationship between enjoyment and anxiety resulted from this discovery, accompanied by varying correlations ranging from negative to positive. Dewaele \& Alfawzan (2018) have also probed into the two emotions in less-tapped foreign-language performance. Apart from the 189 British students in the preceding studies, another group of 152 Saudi English was also investigated in the effect of FLE and FLCA on foreignlanguage performance. Correlation analyses showed that the positive impact of FLE on performance was more substantial than the negative effect of FLCA, a slight more inclination to FLE in FL performance. The complementary qualitative material collected from the Saudi participants shed light on such causes of FLE and FLCA as teachers' well-prepared presentation for the former and malicious pedagogical practices for the latter, as well as their changing decisions on the study of the FL.

In the meantime, Dewaele et al. (2016) have also delved into gender differences in terms of the correlation between anxiety and enjoyment in the foreign language classroom, where randomly selected 1736 FL learners (Female: 1287; Male 449) from around the world were first rated on a Likert scale reflecting various aspects of FLE (Dewaele \& MacIntyre, 2014), and then eight items extracted from the FLCAS (Horwitz et al., 1986). Yet qualitatively, the narrative data were also supplied by open questions on the FLE, which, when combined with the quantitative of individual t-tests, has revealed more interest in FL classrooms and more confidence in their language performance than that of male counterparts, but more solicitude with language mistakes and application, thus a conception of such beneficial emotionality for the use and acquisition as more positive and milder negative emotions.

For all the qualitative approaches to delving into ELE, this considerable portion of studies, if to look into the significant gap from this study, hasn't turned out an entire theoretical construct as the remaining quantitative studies beforehand have never come out with or capitalized on a persuasive framework to look at the emotional development of various target groups. Yet, the quantitative approach can still bring silver lining for this. It invariably features a multidimensional interpretation of research implemented in ways that will consolidate existing theoretical framework or contribute to new construct to some extent. Besides, whatever approaches have been applied, the Chinese context, 
particularly the critical three-year educational stage in senior high schools, has been deficient. However, there have been scant instances in domestic research, and they are relatively small in scope without effective results based on a given theoretical framework. More importantly, ELE here hasn't served as means to their ends, such as an overall theoretical framework, but one of the final proofs for a general picture of a particular group or other research targets. Finally, mired long in the dichotomy between FLCA and FLE before disclosing their overlap, inadequate attention has been endowed for the latter, still another gap from the current study yet an inspirational perspective if a partition is done. Limited efforts have been dedicated to compensating for the gaps except in the conglomeration of quantitative and qualitative approaches towards English language enjoyment which is conducive to and even significant for the current study. They have not been circumscribed with studies utilizing the existing research designs but extended so that a rectified version of the foreign language enjoyment scale has been validated in the Chinese context to explore what Chinese high school students have undergone in their foreign language studies, as conducted by Li Chengchen et al. (2018) to examine the psychometric properties of the FLE scale. The results have come to validate a new scale with 11 items subsumed into three factors, with the dimensions of the highest scores on FLE-Teacher, FLE-Private, and FLE-Atmosphere in the first two stages of research. In contrast, internal and external variables of individual experiences have come into form through Stage 3, which has analyzed qualitative data from 64 participants. The application of this method will result from this elaborated on in the research framework to research ELE of Chinese high school students.

Finally, research on foreign language classroom enjoyment and their effect on foreign language achievement conducted by Jin \& Zhang (2018) has investigated the dimensions of foreign language classroom enjoyment and explored their influences. To this end, 320 first language Chinese Year-1 senior high school students learning English as a foreign language (EFL) have been engaged in adapting the Foreign Language Enjoyment Scale.

Through collecting their mid-term examination scores and factorial analysis, a 3-factor solution has been revealed, including Enjoyment of Teacher Support directly affecting language achievement, and Enjoyment of Student Support, and Foreign Language Learning indirectly affecting it. Thus the study encourages freedom of speech, a reasonable approach to error correction, and cooperative research to foster interaction and collaboration among learners.
Considering the shortage of related research domestically, especially that with broader participants, the current study has been inspired and will take on $\mathrm{Li}$ Chengchen et al.'s (2018) research process. Apart from more excellent participants involved, which will present a comprehensive picture of senior high school students' emotional status of English learning from Year 1 to Year 3, this study will focus on the root causes of students' ELE based on the prevailing test-oriented senior high school English education in China, as compared to Li's validation stage which fell short of contextualized analysis. Finally, if to present an overview of the Chinese context for this study, conflicts between test performance and quality development have formed a precarious balance that tends to fall to the former, with English learning part of students' preparation for their admission to higher education, or what is crowned as "life-changing" opportunity.

This mindset has been permeating into them since Year 1 so that the participants selected will conversely cater to the current research's intent to discover emotional correlates (ELE for this study) of these students' FL learning (Jin \& Zhang, 2018) and to have them optimized by dimension. In so doing, English learning for similar groups of these students to come will gradually grow into a platform to develop their core competencies and language qualities from an emotional perspective rather than a mere device for tests and academic achievements.

\subsection{Research Framework}

For the multi-faceted ELE, the current study will consult the research in terms of language learning enjoyment conducted by Li Chengchen et al. (as in 2.2 of Literature Review on Li et al.'s 2018 paper), where exploratory sequential design was intended to detect the conceptual structure of FLE for Chinese EFL learners. The quantitative data were then collected from her adapted version of Foreign Language Enjoyment Scale by Li Chengchen, Jiang and Dewaele (2018) originally out of Dewaele and MacIntyre $(2014,2016)$ and translated into Chinese after shrinking into 11 items. The dimensions constituting these questions were subsumed into FLE-Private, FLE-Teachers, and FLEatmosphere and were sought based on FLE's theoretical framework, with qualitative data dovetailed within several participants through transcriptions of interviews.

As for their interpretations, FLE-Private refers to its emphasis of private sentiments coalescing around students' achievement and intriguing EFL learning experiences (Li Chengchen et al., 2018), FLE-Teachers its focus on teacher-related EFL learning experiences featuring teachers' support and encouragement, and their versatile pedagogical qualities ( $\mathrm{Li}$ Chengchen et al., 2018), and FLE-atmosphere enjoyable episodes 
throughout classroom learning indicative of enhancing students' learning enjoyment (Li Chengchen et al., 2018). With FLE contextually identified as ELE (English Learning Enjoyment) for the current study, so will its questionnaire render theoretical framework for the current study in terms of ELE in preparation for the general levels of each dimension.

\section{Method}

\subsection{Research Participants}

Three hundred fifty-one participants have been opted from students of stratified academic levels by dint of their schools which were technically subsumed into a demonstrative high school at the provincial or municipal level and an ordinary high school. Two classes within all three academic years from each school were arbitrarily sampled, with genders evenly controlled, irrespective of any ambivalence within each type of school triggered by conformity in academic progress and knowledge foundation, or in overdue relation to their temporary state of study and levels of ELE to justify objectivity of the study. Samples from two classes randomly selected in two high schools of exceptional levels will be conducive to implicating their general level of ELE in that data will be harvested from each school whose general level shall represent their strata of learning competencies, featuring typicality through which to constitute an entire picture of senior high school students concerning their English learning. The participants are as a result of this evenly distributed based on the following parameters in the table:

Table 1. Statistics of Participants by Gender and School Type.

\begin{tabular}{|c|c|c|c|c|c|c|c|c|c|}
\hline \multirow{2}{*}{ Grade } & \multicolumn{4}{|c|}{ Male } & \multicolumn{4}{|c|}{ Female } & \multirow{2}{*}{ Total } \\
\hline & $n_{l}$ & $\%$ & $n_{2}$ & $\%$ & $n_{1}$ & $\%$ & $n_{2}$ & $\%$ & \\
\hline 1 & 28 & 33.7 & 29 & 33.7 & 32 & 35.2 & 29 & 31.9 & 118 \\
\hline 2 & 27 & 32.5 & 29 & 33.7 & 30 & 33.0 & 32 & 35.2 & 118 \\
\hline 3 & 28 & 33.7 & 28 & 32.6 & 29 & 31.9 & 30 & 33.0 & 115 \\
\hline Total & 83 & 23.6 & 86 & 24.5 & 91 & 25.9 & 91 & 25.9 & 351 \\
\hline
\end{tabular}

Notes:

$\mathrm{n}_{1}$ : Sum of Participants from demonstrative high school at provincial or municipal level

$\mathrm{n}_{2}$ : Sum of Participants from ordinary high school

\subsection{Research Instruments}

The current quantitative study will look at its application of Li Chengchen et al.'s (2018) revalidated version of the Foreign Language Enjoyment (FLE) scale, which originated from MacIntyre and Dewaele's 21-item 5-point Likert scale (2014), which ranges from "1" (Strongly disagree) to "5" (Strongly agree). It subsequently established its foundation on their rectified version (2016) more economically with appropriate reliabilities both from an overall perspective (14 items, $\alpha=0.86$ ) and from two constructive factors (i.e., FLEPrivate $\alpha=0.78$; FLE-Social $\alpha=0.87$ ), and has had its primordial dimension of FLE-Social subcategorized into FLE-Teacher and FLE-Environment with its items shrunk into eleven ones after confirming its validity by deleting those of loadings lower than 0.40 for more productive items.

Applied in the English-learning context after being translated into Chinese by the researcher and distributed in ways displayed in Table 1, the freshly developed scale has witnessed its results at acceptable levels after undergoing two rounds of Confirmatory Factor Analysis. In contrast, its application for further analysis has been successively testified by their prominent differentiation among the eleven items $(\mathrm{p}<0.01$ for all) and its internal consistency (i.e., Global $\alpha=0.826$; ELEPrivate's five items, $\alpha=0.792$; ELE-Teacher's three items, $\alpha=0.896$; ELE-Environment's three items, $\alpha=0.778$ ) and split-half reliability indicating high reliability, together with qualitative data collected through interviews which enrich its findings and prove it feasible for the study. 
Table 2. Item Distribution, Reliability and Typical Examples for Each Dimension of ELE in the Questionnaire

\begin{tabular}{cccc}
\hline Dimensions of ELE & Items & $\alpha$ & Sample Questions \\
\hline ELE-Private & 1、2、3、4、6 & 0.868 & $\begin{array}{c}\text { 3. In class, I feel proud of } \\
\text { my accomplishments. }\end{array}$ \\
ELE-Teachers & 7、8、9 & 0.934 & $\begin{array}{c}\text { 7. The teacher is } \\
\text { encouraging. }\end{array}$ \\
ELE-Atmosphere & 5、10、11 & 0.808 & $\begin{array}{c}\text { 5. It's a positive } \\
\text { environment. }\end{array}$ \\
\hline$\alpha:$ the reliability of each dimension in Li's (2018) ELE Scale based on the current study
\end{tabular}

For the current study, which has followed the translated version of the questionnaire, the scale has also seen its results at appropriate levels, testified by their reliability shown in Table 2. (i.e., ELE-Private's five items, $\alpha=0.868$; ELE-Teacher's three items, $\alpha=0.934$; ELE-Environment's three items, $\alpha=0.808$ ) thus further indicating the plausible distribution of the eleven items, and its applicable essence for investigating senior high school students in China in terms of their English learning. From the data's perspective, the current study will share its likelihood with $\mathrm{Li}$ Chengchen's (2018) in genuinely demonstrating the true nature of students' emotional state of English learning. Its results are expected to be congruent with a further qualitative study based on the current quantitative one.

\subsection{Research Procedures}

The following tasks have schematized the current study:

Participant Selection: Around 300 participants were opted from students of stratified academic levels (from senior high schools of different groups) after the final examination to ensure objective and correct data;
Data Collection: The participants were distributed with integrated questionnaires on ELE. The overall data collection and refinement processes were fulfilled on Wenjuanxing, a Chinese online platform for questionnaire design and data collection;

Data Analysis: The data were analyzed through SPSS in terms of parameters related to their general levels both overall and by dimension;

Discussions and Conclusions: Conclusions have been as a result of this generalized based on the results from data analysis, with implications for teachers and future researchers a step forward.

\section{Results}

The descriptive results after data collection for the first eleven items of this comprehensive questionnaire, a complete version of Li Chengchen et al.'s (2017) Foreign Language Enjoyment (or English Learning Enjoyment for this study, ELE) Scale with three dimensions, are displayed in the following Table 3:

Table 3. Descriptive Analysis of ELE

\begin{tabular}{lcccc}
\hline Variables & Min & Max & $M$ & $S D$ \\
\hline ELE-Private & 1.00 & 5.00 & 3.39 & .97 \\
ELE-Teacher & 1.00 & 5.00 & 4.25 & .99 \\
ELE-Atmosphere & 1.00 & 5.00 & 3.27 & 1.04 \\
Overall ELE & 1.00 & 5.00 & 3.59 & .76 \\
\hline
\end{tabular}

A preliminary overview of the statistics has disclosed a medium-high level of ELE ( $M>3$ across the board). From a metacognitive perspective, students' inherent willingness and emotional devotion to their participation in English learning hopefully perpetuated readiness for whatever is unpredictable. Statistics have also seen ELE-teacher with the highest value $(M=4.25)$, with ELE-Private $(\mathrm{M}=3.39)$ and ELE-Atmosphere $(\mathrm{M}=3.27)$ its runners-up, an indicator of students' most significant exposure to teachers throughout English learning. 
Specifically speaking of respective significance, ELE-teacher, a dimension rated with the highest mean value among the three, has reiterated teachers' imperative role in alternating between assiduous inculcation and effective recognition to English learners. Concerning ELE-Private regarding students' perception over English learning in general, the mean value shows its degree close to the overall mean value for ELE scale, therefore representing the authentic mental characteristics of senior high students in English learning that weighs more in personal accomplishments. ELE-Atmosphere, ranking the bottom among three dimensions has looked at its generally positive evaluation on students' surroundings in association with English study (Item 5's M=3.50; Item 10's M=3.56), yet a drastic downfall in the item "we form a tight group" $(M=2.74)$ which eventually downgrades its importance.

An overall statistical picture has demonstrated a resounding justification of the current study's pertinence on data collection, which has been primarily vindicated by this study's relative levels of mean value among variables aligned with Li Chengchen et al.'s (2018). Despite their slight inconsistency with their counterparts in relative levels, the standard deviations have performed a similar attempt to make superior its rather more sporadic levels in ELE-teacher $(\mathrm{SD}=.99)$ and ELE-Atmosphere $(\mathrm{SD}=1.04)$ than the rest, even of close affinity to those of original research. The pertinence of data is also justifiable when the mean value of each dimension is verified to be appropriately enclosed in error bars (Li Chengchen et al., 2018) with which to stipulate its acceptable deviation in the original study's bar chart describing their profiles, robust evidence for data collection as efficacious to depict their general levels.

\section{Discussion}

\subsection{The general levels of ELE-Private}

ELE-Private is seen converging more in egocentric behaviors than in affective attitudes regarding its standard deviation $(\mathrm{SD}=.97)$, in likely relation to scattered samples of distribution of academic achievements. It features an uneven distribution of mean values among each item, with their majority ascending to over 3 (3.48-3.77). In contrast, the item "I feel confident with my English test scores" plummeted to 2.70, which has lagged the overall mean value behind. Students' meager confidence towards their academic results is explanatory in that English examinations for senior high school students, manipulated as a mimicked system of elite selection typical of the annual national Gaokao, will invariably insert their targets into multiple tasks in such latent manner as to obfuscate revision process, particularly for those devoid of their sense of automatic development in language competencies simultaneously with daily blocks of knowledge foundation. Discrepancies from English learning in junior high school, leading to agonizing transformation for Grade One students and leaving fleeting and irrevocable opportunities to progress, have eventually damaged their confidence, even if they can rank in front. On the contrary, those undergoing a smooth transformation of learning methods have taken it for granted to deserve the confidence and excellent test scores, reputations from peers even further. Thus the disparities in test scores, followed by confidence, account for the highest standard deviation of this item $(\mathrm{SD}=1.27)$ among the five items.

Such phenomenon, in hindsight, has also been elucidated by Dewaele et al. (2016) in private feeling from their experiment in which personal feelings were dominantly subcategorized into real-time internal sentiments during the investigation, ranging from pride, pure enjoyment to contentment facing extreme barriers. Besides, the qualitative data were also predominated by prestige derived from their immediate success and satisfaction - pure internal sentiment at work. However, they argued that future research was necessitated to unleash students' conversion in private feelings over an extensive period (Dewaele et al., 2016), which might result in transformed interpretations of enjoyment even with such recurrent recognition as ELE-Teacher within students (Dewaele \& MacIntyre, 2014) to be elucidated in the following 5.2. Among them, in the context of this study, students' adaptability to senior high school English learning, or test-based elite selection system in nature, is represented as a time-consuming and influential factor to observe changes in private feelings, especially students' confidence over their scores. As much as students' exam-based confidence belongs to an essential element to potentially comprise an intact construct of FLE-private, it is noteworthy that its supplementary position is still bolstered by items concerning internal sentiments towards English learning, which explains why items of such in the questionnaire for this study are arranged - four on inner sentiments versus one on confidence with test scoress.

\subsection{The general levels of ELE-Teacher}

A natural interpretation of prevalence in teachers' role from general perception, as indicated in data collection for ELE-Teacher, teachers' encouragement, affection, and countenance in senior high school have attained students' universal acceptance. Be it a cure for their potentially morbid mentality or a savior from their state of being mired in academic drawbacks; this is a perception as panoramic as justified in all the three items averaged above 4 in accordance with the three traits, even though there isn't a unanimous appeal to teachers' efforts to have each member collaborate 
$(\mathrm{SD}=.99)$ on account of teachers' experience or qualities either academically or pedagogically. The result has also been generalized by Jin \& Zhang (2018) while probing into the identical discovery of three dimensions for FLE to $\mathrm{Li}$ et al. (2018) and further illustrated by Dewaele et al. (2016), contending, on the one hand, that teachers' charismatic approaches to their guidance for students of distinctive competencies will promise a rapport throughout classroom learning where capacities of each student shall be separately taken into consideration, and, on the other hand, that teachers' identity accountable for the overall management of students' emotional atmosphere has made it incumbent for them to handle contingencies malicious to classroom stability. In comparison to the context of social communication with which English as a subject has also consented, teachers are dually functioning as an organizer to oversee classroom atmosphere and a motivator to encourage individual's performance.

\subsection{The general levels of ELE-Atmosphere}

Devaluation in ELE-Atmosphere on account of lopsided antipathy towards collaboration in senior high school classroom has frequent recourse contextually sharing similarity with FLE-Private - the educational atmosphere in China that has constantly been conducted under the baton of test-based elite selection system throughout the compacted three years of senior high school. Therefore, for all their helpful enthusiasm hereafter to formulate an environment conducive to English learning, group learning has been discarded for its incongruence to efficiency and competitiveness over rivals, thus eliminating group format in schools of all levels whose solitary expectation is continuously peering at their percentage of admission to higher education.

However, never shall context determine its merits, as has been signified by Strzałka (2016) in his experiment on the Intercultural Communication program that teamwork has factually rekindled students' enthusiasm towards the program against the backdrop of voices of dissent among participants, another indicator of its efficacy. Whatever context the tactic is installed in, dimensionally speaking, it is atmosphere rather than private sentiments that pales when the stability of emotion is entailed, with the prototypical "love" by Petrić et al. (2018) a case in point to maintain positive emotions across students' English learning whether out of its practical significance to personal success or into their unalloyed fascination with the beauty of language. Hence reasonable interpretation will be endowed with students' more inclination to be obtained in ELEPrivate, as conveyed in the results of this study, and subsequently their divergence in terms of their surroundings' influences on English learning (FLE-
Atmosphere's SD=1.04), with their stances discernible from the extent to which their affection towards the English language will endure.endure.

\section{Implications}

Contextualized Dewaele's private feelings (2018) in China's senior high school English teaching are constantly undertaking alternate streams of compliment and criticism for its targeted accomplishment among students of multiple generations. This belongs to a practical approach to academic success currently at significant variance, with stark negligence of subjectbased core competencies. Another pair of controversial standpoints for private feelings which have cropped up out of individuality belongs to a universal recognition over students' development of autonomy, especially functioning in classrooms of authoritarian styles of teaching, and a similar extent of questioning on proper manipulation from overdue individuality that may get students' mind fossilized and teachers undignified. Such binary complexes, as illustrated by the two based on private feelings, will significantly account for a dispute whether to persist in an individual-prone approach to English education or to excavate fresh ground for innovation to fetch its repercussion in the future.

The present study will claim its stance on the latter due to constant innovation at either theoretical or pragmatic levels. Indeed, with a middle-level ELEPrivate weighed significantly for personal accomplishments, the present study does sing its complement to private feelings attempt to cultivate students' autonomy so that they could automatically resort to outbound assistance to their advantage, as long as inappropriate management emotionally. Furthermore, as identical to other quantitative research, the present study will pull out measures of adjustment in accordance with data collection from fieldwork, which thus certifies its feasibility for students and educators alike and indicates its unbiased stance towards a targeted educational approach to improving test-based performance. However, the innovative facet is not without its pitfalls. It is not fresh ground but the primitive private feelings themselves that deserve to be overhauled to agree with optimized measures for English education.

An overhaul based on primitive, instead of fresh ground of private feelings, will witness more excellent elements on quality education imparted in the traditional teaching process, or core competencies of English as a subject as stipulated in National English Curriculum Standards issued in 2017 as Language Ability, Cultural Awareness, Thinking Qualities, and Learning Competencies. Of particular note are the latter three competencies, which are conducive to enriching the original private feelings in ways that will extend 
students' enthusiasm in English learning. To take reading practice, most imperative of all language training sections in senior high school, for example, transitional sessions for the students shall have their private momentum fructified in ways that feature a continuous enclosure of fresh senses of autonomy regarding language competencies, including, and not restricted to, test-related reading materials to be further elaborated on its ethical norms (for narration), its background information for essays on history and culture, and stylistic knowledge for such particular genres as news reports, expositions, and argumentations. Besides, these materials can capitalize on an even cruder approach to transferring students' solitary focus on tests, namely selected reading for the original, where an unabridged version of reading materials will render broader exposure to not only courses of current test development but also their Oliver-like expectation by simply "asking for more" in reading provided that familiar topics or inquisitive phenomena rivet them through various reading opportunities.

With transferred attention fulfilled in preparation for more excellent space to enrich students' private feelings, so come specific measures, for this will encompass reading tasks covering test-oriented training in balanced quantities with cultural perception practices including task-based writing on cultural elements or critical viewpoints, which are also common in items of actual test papers, or with incorporated learning methods for fundamentals between the self-served and teacher-inspected, like vocabulary check and guided assumption on word meaning so that students will gradually develop their English learning competencies rather than merely prepare for monotonous English knowledge check. The shared purpose for all activities above will go to a transferred students' concentration from pure academic success to refined personal qualities whose foundation is laid on their life-related contents and shall promote curiosity over a longer term of their English study since they are from now on capable of discovering more untapped ground to fulfill their English competencies other than a settled terminal for a particular session of learning. By utilizing the predominant position of the contextualized private feelings, enriching them with fresh perspectives for lifelong English capability will enable students' individual-based motivation to function more salubriously and permanently in favorable combination with test-oriented learning where it is adaptable by seeking common grounds between conventional test training and innovations on quality building, and readily observable to see them plunge full speed in their improvement of basic language abilities.to strengthen the contribution and impact of technology exposures to students' academic achievement.

\section{Conclusions}

This study on senior high school students' general levels of ELE, if summarized in order of the significance for each dimension, has emphasized ELETeacher's predominant significance in students' emotional acceptance for possible endeavors academically under the guidance of English teachers. Second, to ELE-Teacher insignificance, ELE-Private has disclosed students' passive and utilitarian nature towards their language learning with such indiscriminative target for each participant as unified national tests, regardless of any formative accomplishments to trigger considerable discrepancies between individuals in affection building, also a backfire to their summative assessments. ELEEnvironment of both the lowest significance and most diverged perception has implicated a clash between the blind quest for efficiency and fulfillment of salubrious private feelings as authentic English learners, and, in close alignment with ELE-Private, signified an integrated causeway straight towards a stabilized emotional development for each senior high school students.

Resolving the fuzziness of students' English Learning Enjoyment that constitutes their emotional status to achieve academic progress, this study is likely to disentangle peer perception from qualitative measurement by channeling it into a positive account of students' emotions. This will somehow bring this study closer to reality, as the essential elements have all been encompassed in the parameter. On the other hand, the negativity can also be revealed without resorting to FLCA that turns out unable to interpret its overlap with FLE or makes it difficult to eliminate its positive repercussion from anxiety. Yet for all the enlightened attempts to bestride into a new epoch of senior high school English teaching and learning, where teachers are preempted with their contributions to the influx of fresh pedagogical ideas, it is the interior of all students that deserves further investigation with which to analyze any possible regression to stimulate an authentic "self" for English learning with the environment of appropriate ambiance co-built by teachers, students and renewed criteria that examine formative progress.

\section{Acknowledgements}

This work was supported by the Project of the Tertiary Education Reform at Northeast Normal University titled "Empowering the English Microteaching Class via PBLI" (Grant No. 421-131003198) and the Project of Discipline Innovation and Advancement (PODIA) - Foreign Language Education Studies at Beijing Foreign Studies University (Grant No. 2020SYLZDXM011) 


\section{References}

Boudreau, C., MacIntyre, P., Dewaele, J. (2018). Enjoyment and Anxiety in Second Language Communication: An Idiodynamic Approach. Studies in Second Language Learning and Teaching Journal, 8(1), 149-170. https://doi.org/10.14746/ssllt.2018.8.1.7.

Csikszentmihalyi, M. (1997). Finding Flow: The Psychology of Engagement with Everyday Life. Harper Collins.

De Smet, A., Mettewie, L. \& Galand, B. (2018). Classroom Anxiety and Enjoyment in CLIL and Non-CLIL: Does the Target Language Matter? Studies in Second Language Learning and Teaching, $\quad 8(1), \quad 47-71$. https://doi.org/10.14746/ssllt.2018.8.1.3.

Dewaele, J., \& Alfawzan, M. (2018). Does the Effect of Enjoyment Outweigh that of Anxiety in Foreign Language Performance?. Studies in Second Language Learning and Teaching, 8(1) , 21-45. https://doi.org/10.14746/ssllt.2018.8.1.2.

Dewaele, J., \& Dewaele, L. (2017). The Dynamic Interactions in Foreign Language Classroom Anxiety and Foreign Language Enjoyment of Pupils Aged 12 to 18: A Pseudo-longitudinal Investigation. Journal of the European Second Language Association, 1(1), 12-22. https://doi.org/10.22599/jesla.6.

Dewaele, J., \& MacIntyre, P. (2014). The Two Faces of Janus? Anxiety and Enjoyment in the Foreign Language Classroom. Studies in Second Language Learning and Teaching, 4(2), 237-274. https://doi.org/10.14746/ssllt.2014.4.2.5.

Dewaele, J., \& MacIntyre, P. (2016). Foreign Language Enjoyment and Foreign Language Classroom Anxiety: The Right and Left Feet of the Language Learner. In Positive Psychology in SLA (pp. 215236). Multilingual Matters. https://doi.org/10.21832/9781783095360-010.

Dewaele, J., MacIntyre, P., Boudreau, C., \& Dewaele, L. (2016). Do Girls Have All the Fun? Anxiety and Enjoyment in the Foreign Language Classroom. Theory and Practice of Second Language Acquisition, 2(1), 41-63.

Dewaele, J., Witney, J., Saito, K., \& Dewaele, L. (2017). Foreign Language Enjoyment and Anxiety: The Effect of Teacher and Learner Variables. Language Teaching Research, 22(6), 676-697. https://doi.org/10.1177/1362168817692161.
Gałajda, A. Wojtaszek, \& P. Zakrajewski (Eds.). Multiculturalism, Multilingualism and the Self: Studies in Linguistics and Language Learning (pp. 97-111). Springer International Publishing. https://doi.org/10.1007/978-3-319-56892-8 7.

Gregersen, T., MacIntyre, P. \& Finegan, K. (2014). Examining Emotional Intelligence within the Context of Positive Psychology Interventions. Studies in Second Language Learning and Teaching, 4(2), 327-353. https://doi.org/10.14746/ssllt.2014.4.2.8.

Horwitz, K., Horwitz, B., Cope, J. (1986). Foreign Language Classroom Anxiety. The Modern Language Journal 70(2), 125-132. https://doi.org/10.2307/327317.

Jiang, G., \& Li, C. (2017). SLA research in the Positive Psychology perspective: Review and prospects. Foreign Language World, 5, 32-39.

Jin, Y., \& Dewaele, J. (2018). The Effect of Positive Orientation and Perceived Social Support on Foreign Language Classroom Anxiety. System, 74, $149-157$. https://doi.org/10.1016/j.system.2018.01.002.

Jin, Y., \& Zhang, L. (2018). The Dimensions of Foreign Language Classroom Enjoyment and Their Effect on Foreign Language Achievement. International Journal of Bilingual Education and Bilingualism, 24(7), 948-962. https://doi.org/10.1080/13670050.2018.1526253.

Li, C., Jiang, G., \& Dewaele, J. (2018). Understanding Chinese High School Students' Foreign Language Enjoyment: Validation of the Chinese Version of the Foreign Language Enjoyment Scale. System, 76 , 183-196. https://doi.org/10.1016/j.system.2018.06.004.

Liu, H., \& Song, X. (2021). Exploring "Flow" in Young Chinese EFL Learners' Online English Learning Activities. System, 96, 1-13. https://doi.org/10.1016/j.system.2020.102425.

MacIntyre, P. (2016). So Far so Good: An Overview of Positive Psychology and Its Contributions to SLA. In D. Gabrys-Barker, \& D. Gałajda (Eds.), Positive Psychology Perspectives on Foreign Language Learning and Teaching (pp. 3-20). Springer International Publishing. https://doi.org/10.1007/978-3-319-32954-3 1.

MacIntyre, P. (2017). An overview of language anxiety research and trends in its development. In $\mathrm{C}$. Gkonou, M. Daubney, \& J. Dewaele (Eds.), New Insights into Language Anxiety: Theory, Research and Educational Implications (pp. 11-30). 
Multilingual

Matters. https://doi.org/10.21832/9781783097722-003.

MacIntyre, P., \& Gregersen, T. (2012). Emotions that facilitate language learning: The positivebroadening power of the imagination. Studies in Second Language Learning and Teaching, 2(2), 193-213. https://doi.org/10.14746/ssllt.2012.2.2.4.

MacIntyre, P., \& Mercer, S. (2014). Introducing Positive Psychology to SLA. Studies in Second Language Learning and Teaching, 4(2), 153-172. https://doi.org/10.14746/ssllt.2014.4.2.2.

Ministry of Education of the People's Republic of China. (2017). General Senior High School Curriculum Standards (English) (2017 Edition). People's Education Press.

Oxford, R., \& Cuéllar, L. (2014). Positive Psychology in Cross-cultural Narratives: Mexican Students Discover Themselves while Learning Chinese. Studies in Second Language Learning and Teaching, 4(2), 173-203. https://doi.org/10.14746/ssllt.2014.4.2.3.

Pavelescu, L., \& Petrić, B. (2018). Love and Enjoyment in Context: Four Case studies of Adolescent EFL Learners. Studies in Second Language Learning and Teaching, 8(1), 73-101. https://doi.org/10.14746/ssllt.2018.8.1.4.

Pekrun, R., Maier, A., \& Elliot, J. (2009). Achievement Goals and Achievement Emotions: Testing a Model of Their Relations with Academic Performance. Journal of Educational Psychology, 101(1), $115-135$. http://dx.doi.org/10.1037/a0013383.

Piechurska-Kuciel, E. (2017). L2 or L3? Foreign language enjoyment and proficiency. In Multiculturalism, multilingualism and the self (pp. 97-111). Springer, Cham.

Piniel, K., \& Albert, Á. (2018). Advanced Learners' Foreign Language-related Emotions across the Four Skills. Studies in Second Language Learning and Teaching, 8(1), 127-147. https://doi.org/10.14746/ssllt.2018.8.1.6.

Strzałka, A. (2016). Can earning academic credits be enjoyable? Positive psychology in a university course of intercultural communication. In Positive Psychology Perspectives on Foreign Language Learning and Teaching (pp. 307-321). Springer, Cham.. 